\title{
Application of the Improved City Blueprint Framework in 45 Municipalities and Regions
}

\author{
Steven H. A. Koop ${ }^{1,2}$ • Cornelis J. van Leeuwen ${ }^{1,2}$
}

Received: 21 April 2015 /Accepted: 28 July 2015 /

Published online: 19 August 2015

(C) The Author(s) 2015. This article is published with open access at Springerlink.com

\begin{abstract}
Rapid urbanization, water pollution, climate change and inadequate maintenance of water and wastewater infrastructures in cities may lead to flooding, water scarcity, adverse health effects, and rehabilitation costs that may overwhelm the resilience of cities. Furthermore, Integrated Water Resources Management (IWRM) is hindered by water governance gaps. We have analyzed IWRM in 45 municipalities and regions divided over 27 countries using the improved City Blueprint ${ }^{\circledR}$ Framework (CBF). The CBF incorporates solely performance-oriented indicators that more accurately measure the city's own efforts and performances to improve its IWRM. We have also analyzed the trends and pressures (on which the city's IWRM has a negligible influence). The Trends and Pressure Framework (TPF) creates awareness of the most stressing topics that either hamper or, on the contrary, pose opportunity windows for IWRM. The improved Blue City Index (BCI*) and the Trends and Pressures Index (TPI; the arithmetic mean of all TPF indicators) have been compared with other city descriptors. The $\mathrm{BCI}^{*}$ and TPI showed a significant and negative Pearson correlation $(r=-0.83)$. This implies that cities with pressing needs to improve their IWRM also face the highest environmental, financial and/or social limitations. The BCI* and TPI correlate significantly with the ND-GAIN climate readiness index $(r=0.86 ; r=-0.94)$, the environmental awareness index $(r=0.85 ; r=-0.85)$, the European green city index $(r=0.86 ; r=-0.85)$ and various World Bank governance indicators. Based on a hierarchical clustering of the 45 municipalities and regions, 5 different levels of sustainability of urban IWRM could be distinguished, i.e., (1) cities lacking basic water services, (2) wasteful cities, (3) water efficient cities, (4) resource efficient and adaptive cities, and (5) water wise cities. This categorization, as well as the CBF and TPF are heuristic approaches to speed up the transition towards water wise cities.
\end{abstract}

Cornelis J. van Leeuwen

Kees.van.Leeuwen@kwrwater.nl

1 KWR Watercycle Research Institute, Groningenhaven 7, Nieuwegein 3433 PE, The Netherlands

2 Copernicus Institute for Sustainable Development and Innovation, Utrecht University, Heidelberglaan 2, Utrecht 3584 CS, The Netherlands 
Keywords Water management $\cdot$ Climate adaptation $\cdot$ Sustainability indicators $\cdot$ Blue City Index ${ }^{\circledR}$. Waste treatment

\section{Introduction}

\subsection{The Challenges of Urban Water Governance}

Management of fresh water resources is of critical importance to the healthy social, economic and political well-being of a society. Stresses exerted on the world's water resources by the increasing demand from growing populations with changing consumption patterns, the detoriation of water quality by pollution and climate change are placing water increasingly higher on the international agenda (UNEP 2012; EC 2012; Hoekstra and Wiedman 2014; World Economic Forum 2014). These megatrends pose urgent water challenges, particularly in cities (Engel et al. 2011; SIWI 2012; Van Leeuwen 2013; Chong 2014; MacDonald et al. 2014; Koop and Van Leeuwen 2015a).

Conventional urban water management is often fragmented and relies on traditional, technical and linear management approaches (Brown and Farrelly 2009; Ferguson et al. 2013). Furthermore, it is often inflexible, energy intensive and tends to focus on short-term solutions disregarding long-term cost-effectiveness or sustainability (Philip et al. 2011). Despite significant progression in technical solutions such as advancements in water, wastewater and stormwater treatment technologies, the transition from conventional to more sustainable Integrated Water Resources Management (IWRM) is slow (Van de Meene et al. 2011).

Various governance aspects such as institutional inertia and inter-organizational barriers, are forming large limitations for IWRM. Brown and Farrelly (2009) identified a variety of institutional barriers concerning IWRM that fit well within the 7 major governance gaps that have been distinguished by the Organization of Economic Co-operation and Development (OECD; Table 1).

About two-thirds of the OECD countries experienced a mismatch between the administrative responsibilities and available funding. Also insufficient scientific, technical and infrastructural

Table 1 The OECD multi-level governance framework: key co-ordination gaps in water policy (OECD 2011)

1. Administrative gap Geographical 'mismatch' between hydrological and administrative boundaries. This can be at the origin of resource and supply gaps.

2. Information gap

Asymmetries of information (quantity, quality, type) between different stakeholders involved in water policy, either voluntary or not.

3. Policy gap

Sectoral fragmentation of water-related tasks across ministries and agencies.

4. Capacity gap

Insufficient scientific, technical, infrastructural capacity of local actors to design and implement water policies (size and quality of infrastructure, etc.) as well as relevant strategies.

5. Funding gap

Unstable or insufficient revenues undermining effective implementation of water responsibilities at subnational level, cross-sectoral policies, and investments requested.

6. Objective gap

Different rationales creating obstacles for adopting convergent targets, especially in case of motivational gap (referring to the problems of reduced political will to engage substantially in organizing the water sector).

7. Accountability gap Difficulty in ensuring the transparency of practices across the different constituencies, mainly due to insufficient users' commitment, lack of concern, awareness and participation. 
capacity of local actors was reported in two-thirds of the countries. Many countries face a policy gap due to fragmentation of responsibilities and a lack of coordination between different policy fields. Finally, administration, information and accountability gaps were found for more than half of the OECD countries. These barriers are mostly intra- and inter-organizational, implying that knowledge and technology often form no limitation. Unfortunately, often, a joint vision and effective cooperation amongst institutions and communities is lacking. Hence, there is a need for an integrated long-term vision and planning, including adequate allocation of responsibilities and funding, in which all relevant stakeholders are involved already at an early stage (EC 2015a). This is a highly difficult task since urban water managers are being confronted with increasingly complex and multi-faceted challenges due to climate change, urban growth, resource limitations and societal expectations (Brown and Farrelly 2009; OECD 2011; EEA 2014a; OECD 2015). For the non-OECD countries it can be assumed that the water governance gaps as shown in Table 1, are even greater.

\subsection{Promoting a Transition Towards Sustainable IWRM}

Although there is a general recognition of the urban water challenges and water governance gaps, attempts to develop tools to overcome these barriers by stimulating the implementation of IWRM are often lacking (Van de Meene et al. 2011; Brown and Farrelly 2009). Because a significant proportion of IWRM practices are locally implemented, local decision-making processes provide important pathways for long-term planning (Floyd et al. 2014; Brown and Farrelly 2009). Globally, approximately $80 \%$ of the GDP is produced in cities, and also $75 \%$ of the energy and materials are consumed in cities (UNEP 2013). Therefore, global environmental pressures and long-term preservation of quality of life are largely determined by urban systems. Hence, the fostering of sustainable IWRM is most effective in cities.

First step in fostering sustainable IWRM is a description of the current state, thereby creating awareness, and identifying the most viable opportunities (Philip et al. 2011). Wong and Brown (2009) identified three pillars that should be integrated in IWRM to attain water wise or water sensitive cities: (I) cities as water supply catchments, using diverse centralized and decentralized water sources; (II) cities as providers of ecosystem services that prevent the surrounding environment for degradation and depletion as well as promoting urban biodiversity; (III) cities hosting water sensitive communities that promote sustainable decision making and behavior. Their three pillar approach aspires: (I) integration between water planning and urban planning; (II) (climate) adaptive and multi-functional infrastructure; and (III) collaboration between science, policy, practice and community. No water wise or water sensitive city is until yet realized and there is no accepted set of attributes and indicators that define it (Ferguson et al. 2013). However, since indicators are values or parameters that are able to point to, provide information about, and describe the current state, with a significance that extends beyond that directly associated with the parameter value, a balanced indicator framework can provide an important first step in promoting IWRM (OECD 2003; Van Leeuwen et al. 2012). Most existing indicators are not standardized, consistent, or comparable over time or between cities (ISO 2014). This hampers the exchange of knowledge, experiences, and best practices between cities and thereby the transition of cities towards water wise or water sensitive cities. This needs to change as the urban water challenges become increasingly urgent (Van Leeuwen 2013; EC 2015a). We have highlighted these IWRM challenges and performances in detailed reports for the cities of Rotterdam (Van Leeuwen et al. 2012), Dar es Salaam (Van Leeuwen and Chandy 2013), Hamburg (Van Leeuwen and Bertram 2013), 
Amsterdam (Van Leeuwen and Sjerps 2015a), Istanbul (Van Leeuwen and Sjerps 2015b), Ho Chi Minh City (Van Leeuwen et al. 2015) and Melbourne.

\section{Methodology}

The City Blueprint Framework (CBF) is a first attempt to perform a baseline assessment of IWRM (Van Leeuwen et al. 2012) and the baseline assessment has been applied on 11 cities (Van Leeuwen 2013) and recently on 45 municipalities and regions, mainly in Europe (Koop and Van Leeuwen 2015b; EC 2015a). The City Blueprint ${ }^{\circledR}$ is a baseline assessment or quick scan that evaluates the actual state of a city's IWRM and shows the indicator results in a spider diagram. It is a first step in the strategic planning process of IWRM in cities (Philip et al. 2011).The City Blueprint allows for comparison with other leading cities and, thereby can promote city-to-city learning (EC 2015a). The City Blueprint process is an interactive approach that involves all stakeholders early on in the process. It is a first step in the strategic understanding and long-term planning of IWRM in cities. Major stakeholders include water utilities, water boards, city councils, companies, Non-Governmental Organizations etcetera.

Based on constructive feedback from cities we have recently revised the CBF and the results will be published in this journal (Koop and Van Leeuwen 2015a). We now distinguish two separate frameworks, i.e., a Trends and Pressures Framework (TPF; Table 2) and a performance-oriented CBF (Table 3). The TPF provides a wider context that is supplementary to the CBF. The TPF is composed of 12 descriptive indicators that are equally distributed according to the triple bottom line approach (Elkington 1998; Mori and Yamashita 2015). In this way, the TPF may create awareness of the most stressing topics that either hamper or, on the contrary, pose opportunity windows for IWRM. The CBF has been updated to incorporate solely performance-oriented indicators that more accurately measure the city's own efforts,

Table 2 Basic method and features of the Trends and Pressures Framework (TPF)

\begin{tabular}{|c|c|c|}
\hline Goal & \multicolumn{2}{|c|}{ Baseline performance assessment of the sustainability of urban IWRM } \\
\hline \multirow[t]{12}{*}{ Framework } & Social pressures & 1. Urbanization rate \\
\hline & & 2. Burden of disease \\
\hline & & 3. Education rate \\
\hline & & 4. Political instability \\
\hline & Environmental pressures & 5. Flooding \\
\hline & & 6. Water scarcity \\
\hline & & 7. Water quality \\
\hline & & 8. Heat risk \\
\hline & Financial pressures & 9. Economic pressure \\
\hline & & 10. Unemployment rate \\
\hline & & 11. Poverty rate \\
\hline & & 12. Inflation rate \\
\hline Data & \multicolumn{2}{|c|}{ Public data or data provided by the water utilities } \\
\hline Scores & \multicolumn{2}{|c|}{0 : no concern, 1 : little concern, 2 : medium concern, 3 : concern and, 4: great concern } \\
\hline Overall score & \multicolumn{2}{|c|}{$\begin{array}{l}\text { Trends and Pressures Index (TPI), the arithmetic mean of } 12 \text { indicators. Indicators scoring a } \\
\text { concern or great concern ( } 3 \text { or } 4 \text { points) are marked and communicated to the stakeholders. }\end{array}$} \\
\hline
\end{tabular}


Table 3 Basic method and features of the improved City Blueprint Framework (CBF)

\begin{tabular}{|c|c|}
\hline Goal & Baseline performance assessment of the state of IWRM \\
\hline Framework & $\begin{array}{l}\text { Twenty-five indicators divided over seven broad categories: } \\
\text { 1. Water quality } \\
\text { 2. Solid waste treatment } \\
\text { 3. Basic water services } \\
\text { 4. Wastewater treatment } \\
\text { 5. Infrastructure } \\
\text { 6. Climate robustness } \\
\text { 7. Governance }\end{array}$ \\
\hline Data & $\begin{array}{l}\text { Public data or data provided by the (waste)water utilities and cities based on a questionnaire (EC } \\
\text { 2015a) }\end{array}$ \\
\hline Scores & 0 (bad performance) to 10 (excellent performance) \\
\hline $\begin{array}{l}\text { Overall } \\
\text { score }\end{array}$ & Blue City Index ${ }^{\circledR}\left(\mathrm{BCI}^{*}\right)$, the geometric mean of 25 indicators varying from 0 to 10 . \\
\hline
\end{tabular}

performances and possibilities to improve IWRM. A detailed description of the data sources and scoring methods are described elsewhere (EC 2015a; Koop and Van Leeuwen 2015b).

In this paper we review IWRM in the following 45 municipalities and regions, mainly in Europe. In the rest of this paper these municipalities and regions will be referred to as cities.

\begin{tabular}{lll}
\hline Algarve (Portugal) & Amsterdam (The Netherlands) & Ankara (Turkey) \\
Athens (Greece) & Belém (Brazil) & Berlin (Germany) \\
Bologna (Italy) & Bucharest (Romania) & Budapest (Hungary) \\
Copenhagen (Denmark) & Dar es Salaam (Tanzania) & Dordrecht (The Netherlands) \\
Eindhoven (The Netherlands) & Eslov (Sweden) & Galati (Romania) \\
Genova (Italy) & Hamburg (Germany) & Helsingborg (Sweden) \\
Helsinki (Finland) & Ho Chi Minh City (Vietnam) & Istanbul (Turkey) \\
Jerusalem (Israel) & Kilamba Kiaxi (Angola) & Kristianstad (Sweden) \\
Ljubljana (Slovenia) & Lodz (Poland) & London (UK) \\
Lyon (France) & Maastricht (The Netherlands) & Malmö (Sweden) \\
Malta (Malta) & Manresa (Spain) & Melbourne (Australia) \\
New York (USA) & Nieuwegein (The Netherlands) & Oslo (Norway) \\
Reggio Emilia (Italy) & Reykjavic (Iceland) & Rotterdam (The Netherlands) \\
Scotland (UK) & Stockholm (Sweden) & Varna (Bulgaria) \\
Venlo (The Netherlands) & Wroclaw (Poland) & Zaragoza (Spain) \\
\hline
\end{tabular}

The paper summarizes the most important results of the improved $\mathrm{CBF}\left(\mathrm{CBF}^{*}\right)$ and TPF and compares this with the previous $\mathrm{CBF}$ by using the assessments of 45 cities, mainly in Europe. Next the overall score of the improved Blue City Index ${ }^{\circledR}\left(\mathrm{BCI}^{*}\right)$ and the TPI (the arithmetic mean of the 12 TPF indicators) are compared with other indices and city discriptors. All city descriptors and the $\mathrm{BCI}^{*}$ are tested to meet the requirements for Pearson correlations, i.e., being an interval or ratio level, the assumption of linearity and normality by applying the Shapiro-Wilk test using SPSS software. Finally, based on a hierarchical clustering analyses, $\mathrm{BCI}^{*}$ scores and key indicator results, a heuristic categorization of different levels of sustainability of urban IWRM is proposed. 


\section{Results}

\subsection{Trends and Pressures}

The social, financial and environmental setting of every city is unique. This context may result in different priorities per city and their ability to attain sustainable IWRM. Indicators aimed to foster sustainable IWRM, should measure solely IWRM performances. A typical example is the limited natural availability of fresh water which may cause water stress for cities in (semi)arid regions. In this case, descriptive indicators measuring water availability would score low while the city may be a frontrunner in water efficiency practices precisely because they have to cope with limited water resources. Solely measuring urban performance to reduce water consumption allows for a fair comparison between cities and, more importantly, fosters sustainable practices in all cities participating in a city-to-city learning alliance. The main task of the TPF here is to identify priorities. In this case priorities may be the application of water saving measures by consumers, as well as infrastructure leakage reduction by water utilities. Hence, the TPF provides a wider context and allows for a quick overview of the most important limitations and windows of opportunity for IWRM.

Urban environmental pressures need to be reduced while social and financial living standards have to be sufficient to enable a good quality of life (Mori and Yamashita 2015). Hence, social, environmental and financial aspects are considered as equally important and are therefore covered by an equal number of indicators. All 12 indicators (Table 2) are scaled from 0 to 4 points, and the following classes have been used: $0-0.5$ points (no concern), 0.5-1.5 (little concern), 1.5-2.5 (medium concern), 2.5-3.5 (concern), and 3.5-4 (great concern). Figure 1 shows the result of the aggregated score, i.e., the TPI for the 45 cities. The overall TPI provides a basic overview of the social, environmental and financial pressures. All cities in north western Europe have low TPIs. Mediterranean and eastern European cities already experience moderate pressures, while big cities such as Belém, Ho Chi Minh City, Istanbul, Dar es Salaam and Kilamba Kiaxi have high TPIs.

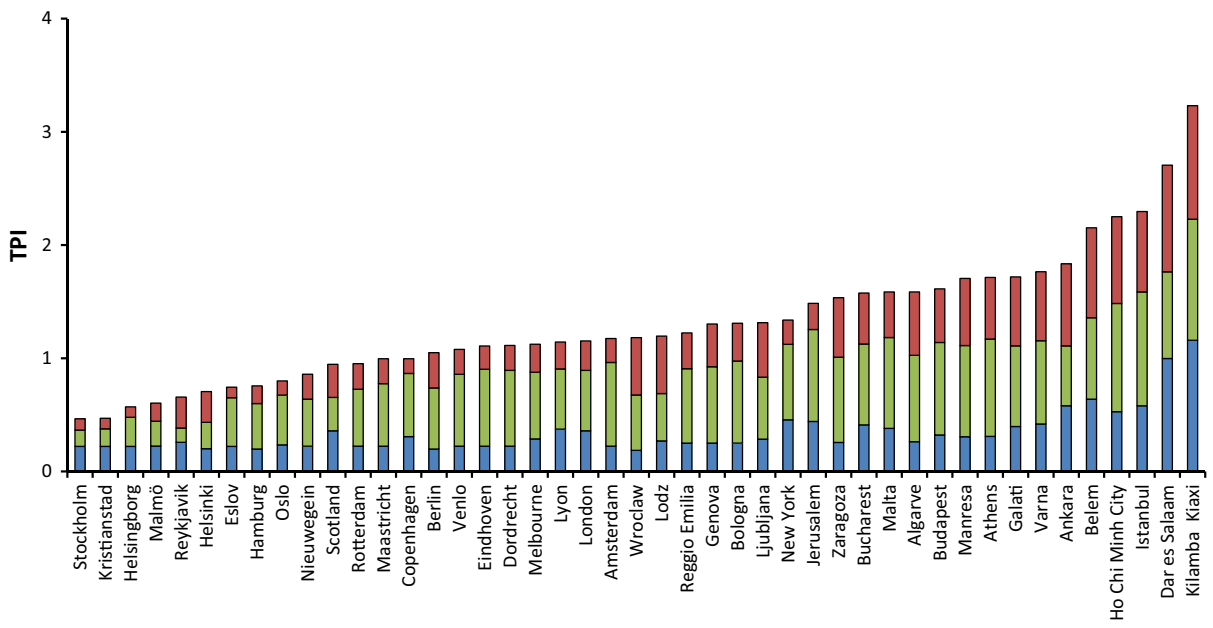

Fig. 1 The Trends and Pressures Index (TPI; the arithmetic average of all 12 indicators). Green, red and blue represent the share of the environmental, financial and social indicators, respectively to the overall TPI of each of the 45 cities 


\subsection{The Improved City Blueprint Framework}

The CBF has been modified to obtain an approximately proportional contribution of all indicators and categories to the overall score, i.e., the improved BCI (BCI*). This was done by analyzing correlations and variances, as well as by balancing and regrouping the different indicators. Six indicators have been removed because of data inaccuracy, overlap / redundancy, or lack of focus on IWRM. Seven indicators have been added, i.e., secondary and tertiary wastewater treatment (WWT), operation cost recovery, green space and three indicators belonging to the category 'solid waste treatment'. Furthermore, the geometric aggregation method has been selected for the calculation of the $\mathrm{BCI} *$ because it emphasizes the integrative nature of IWRM by penalizing unbalanced indicator scores (Koop and Van Leeuwen 2015a).

The BCI (arithmetic average of the old 24 indicators) and the BCI* have been calculated for the same 45 cities. The $\mathrm{BCI}^{*}$ shows more distinctiveness compared to $\mathrm{BCI}$, since the variance is 2.5 times larger. The BCI ranges from 3.6 for the city of Belém (Brazil) to 8.5 for the city of Helsingborg (Sweden) which is a difference of 5.1 points. The $\mathrm{BCI}^{*}$ ranges from 1.1 for the city of Belém (Brazil) to 8.3 for the city of Amsterdam (Netherlands) which is a difference of 7.2 points. The differences in the $\mathrm{BCI}$ and the $\mathrm{BCI} *$ are shown in Fig. 2.

Cities that already received a low BCI got even lower BCI* scores. On the contrary, cities that already had high BCIs, received slightly lower BCIs*. The city of Amsterdam is an exception (Fig. 2). The lower scoring cities showed the largest decrease in the overall BCI* compared to their old BCI, which is the result of the geometric aggregated mean as this method penalizes unbalanced scores. The ranking of the cities has not changed considerably and the $\mathrm{BCI}$ and $\mathrm{BCI}^{*}$ correlate strongly with a Pearson correlation coefficient (r) of 0.92 (Fig. 3). The BCI* is negatively correlated with the overall TPI ( $r=-0.83$; Fig. 3 ). Cities that experience high social, environmental and/or financial pressures, generally perform low on IWRM.

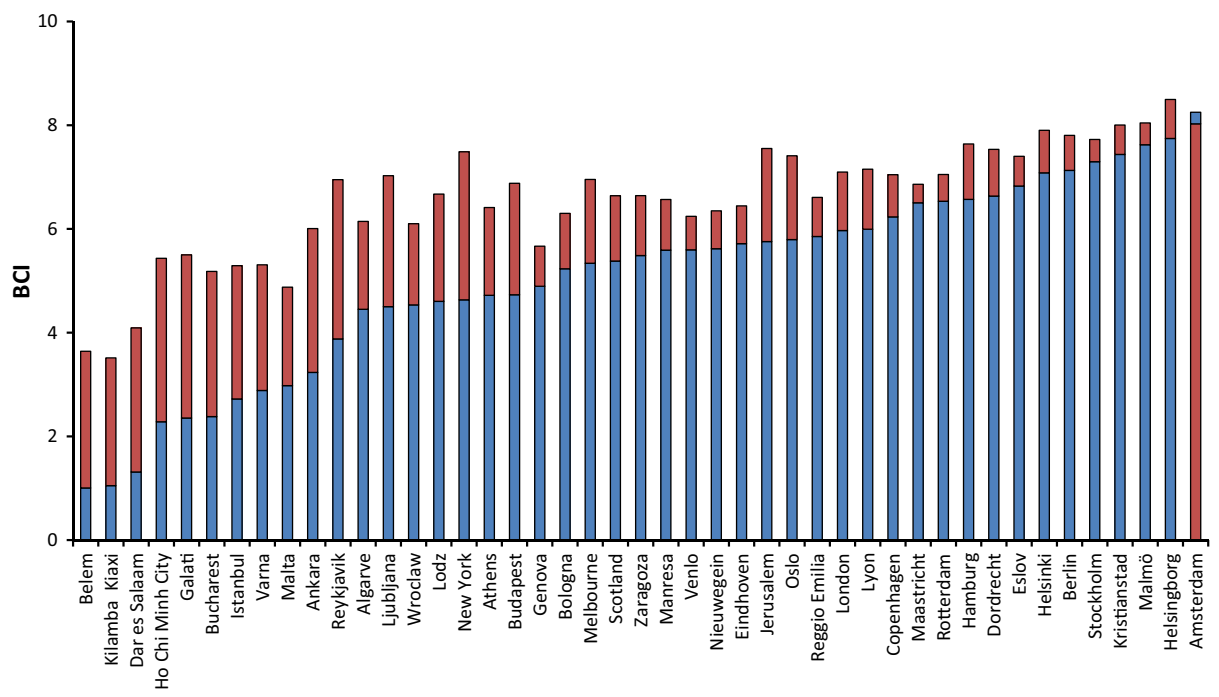

Fig. 2 The old Blue City Index (BCI; in red) compared to improved BCI (BCI* in blue). In general the BCI* is lower because of the more performance-oriented indicators and geometric aggregation method. Only the city of Amsterdam has a slightly higher BCI* 

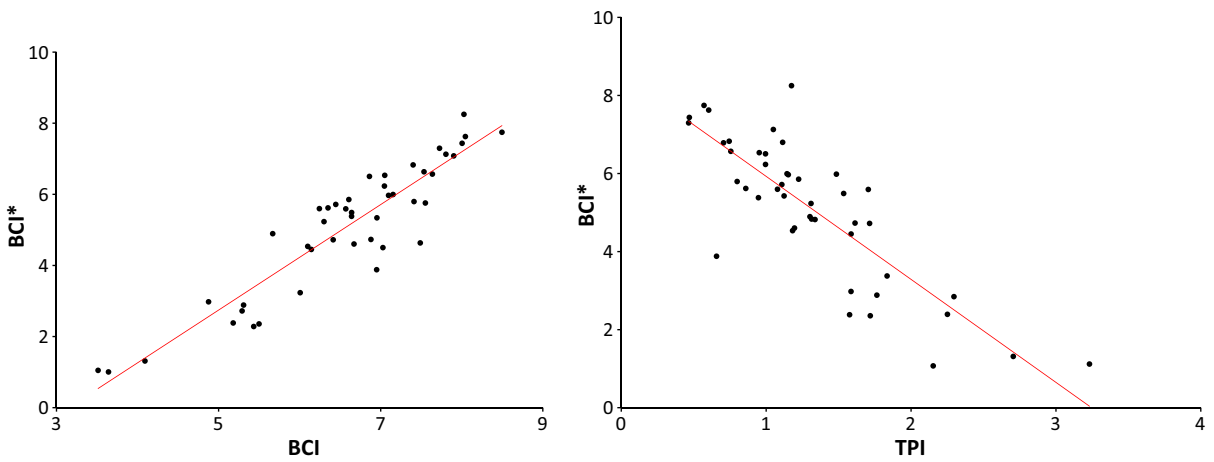

Fig. 3 The BCI of the current $\mathrm{CBF}$ and improved $\mathrm{CBF}$ are highly correlated (left; $r=0.92)$. The BCI* shows a negative correlation with the TPI showing that cities experiencing high environmental, financial and/or social pressures also have low BCI* scores (right; $r=-0.83$ )

The BCI* and TPI have been compared with other indices and parameters that describe the state of cities and countries. It should be emphasized that correlations are not cause-effect relations. The BCI* correlated remarkably well with the Notre Dame Global Adaptation Index (ND-GAIN) climate readiness index $(r=0.86)$. This index measures the country's ability to absorb financial resources and mobilize them efficiently to adapt to climate change by taking into account economic, governance and social factors that contribute with 50, 25 and $25 \%$, respectively (ND-GAIN 2013). The ND-GAIN climate readiness index correlated highly with the BCI* (Fig. 4) and even better, but negatively, with the TPI ( $r=-0.94$; Table 4). It means that cities that perform well on IWRM are cities that are also climate-ready.

Other correlations between the BCI* and TPI show the same pattern and are summarized in Table 4. Interestingly, the $\mathrm{BCI}^{*}$ is also strongly correlated with the Environmental Awareness Index (EAI; Harju-Autti and Kokkinen 2014). Furthermore, correlations with public participation, measured by the involvement in voluntary work are high (EFILWC 2012). The BCI* and TPI correlate very well with all World Bank governance indicators (World Bank 2015), in particular with government effectiveness.
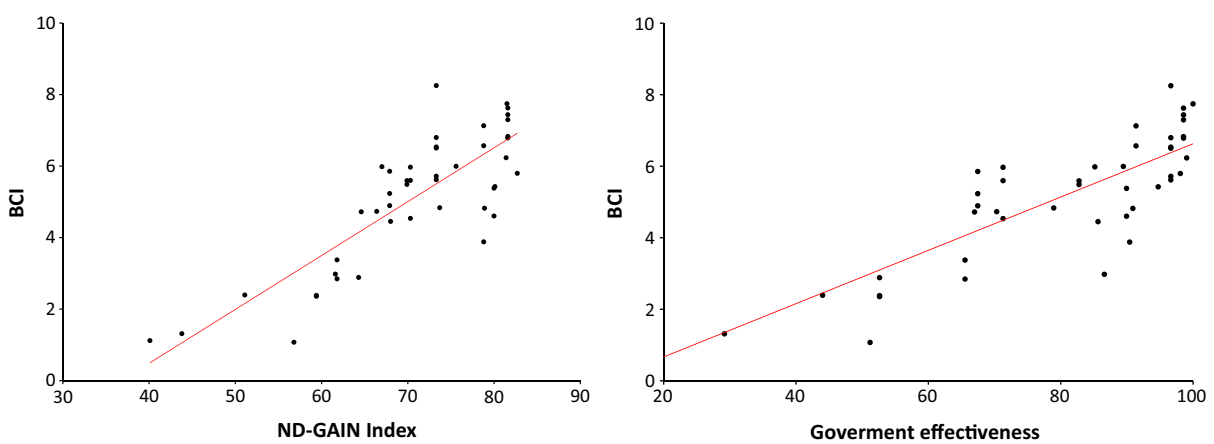

Fig. 4 The BCI* is highly correlated with the ND-GAIN climate readiness index and the Government effectiveness index (ND-GAIN 2013; World Bank 2015) 
Table 4 Correlations of the BCI* and TPI with various indices and city descriptors. All correlation coefficient are highly significant (maximum $p<10^{-5}$ )

\begin{tabular}{llll}
\hline & BCI* & TPI & Source \\
\hline ND-GAIN climate readiness & 0.86 & -0.94 & ND-GAIN 2013 \\
Green city index & 0.86 & -0.85 & Siemens 2015 \\
Involvement in voluntary work & 0.86 & -0.81 & EFILWC 2012 \\
Environmental awareness index & 0.85 & -0.84 & Harju-Autti and Kokkinen 2014 \\
Government effectiveness & 0.84 & -0.88 & World Bank 2015 \\
Regulatory quality & 0.83 & -0.90 & World Bank 2015 \\
Rule of law & 0.82 & -0.89 & World Bank 2015 \\
Voice \& accountability & 0.81 & -0.90 & World Bank 2015 \\
Control of corruption & 0.80 & -0.89 & World Bank 2015 \\
GDP per capita & 0.72 & -0.75 & IMF 2013 \\
IWRM ambitions & a & -0.59 & EC 2015a \\
\hline
\end{tabular}

${ }^{\text {a }}$ Because, IWRM ambitions is a CBF indicator, the shown correlation has been calculated with the BCI* calculated without this indicator (i.e. based on 24 instead of 25 indicators)

\subsection{Performance of Cities: Main Results}

It is impossible to address the detailed results of each and every City Blueprint and TPF of the 45 cities, but examples for cities have been provided by Koop and Van Leeuwen (2015a, $2015 b$ ). In this paper we summarize the main findings.

The lack of basic water services and the absence of environmental protection measures in cities in developing and transition countries, such as Dar es Salaam, Ho Chi Minh City, Belém and Istanbul is staggering. These cities have a secondary WWT coverage of less than $30 \%$. Overall, still 11 of the 45 cities have secondary WWT coverage of less than $50 \%$. These low coverages pose serious threats to ecosystem and human health. For 19 of the 45 cities and regions, tertiary WWT is below $50 \%$ coverage. This includes all eastern European cities, whereas most cities in western Europe have high coverages.

Nutrient recovery from wastewater is important to decrease surface water pollution as well as to reduce our dependency on non-renewable resources. This holds especially for phosphorous and potassium as these resources will become increasingly expensive as they are difficult to obtain (Cordell and White 2011; EC 2014). About half of the cities do not apply any form of nutrient recovery. The reuse of nutrients can either be done directly by applying sewage sludge on agricultural land or indirectly by producing struvite $(\mathrm{MgNH} 4 \mathrm{PO} 4.6 \mathrm{H} 2 \mathrm{O})$ from wastewater. Struvite can be used as a fertilizer, e.g. in parks or sport fields as is done in Amsterdam (Van Leeuwen and Sjerps 2015a). The production of struvite is a good alternative if direct application of sewage sludge is legally restricted or banned as a result of health or economic concerns. Currently, many cities do not apply nutrient recovery because they are either not aware or a market to apply struvite is lacking.

Eleven cities do not apply any form of energy recovery techniques at the wastewater treatment plants while this can be considered as a $\mathrm{CO}_{2}$-neutral way of energy generation. Moreover, 30 cities used less than $50 \%$ of their potential to apply energy recovery from their solid waste. German cities even burn $21 \%$ of their total solid waste without energy recovery (OECD 2013). On average $47 \%$ of the solid waste ends up in landfills where it produces large 
amounts of greenhouse gasses and may lead to water pollution, especially when the site management is insufficient ( Rosik-Dulewska et al. 2007; Lazarevic et al. 2010).

The average infrastructure leakage rate for 45 cities and regions is considerable, i.e., $21 \%$. Seven cities had leakage rates that exceeded $40 \%$. Stormwater separation is applied in $49 \%$ of the water infrastructures in the cities in this study. It is remarkable that Copenhagen and almost all Dutch cities have high BCIs* but low separation rates (less than $12 \%$ ). As a consequence, combined sewage overflows, urban drainage flooding, both exacerbated by climate change, may seriously affect water quality and biodiversity. This may lead to damages from extreme weather events that are projected to increase significantly (Jongman et al. 2014).

Green space coverages (\%) differed largely per city with $40 \%$ or more for most Scandinavian cities and on the other hand less than $15 \%$ for Athens, Bucharest and all developing cities. A low share of green area increases the vulnerability to urban drainage floods and heat waves (EEA 2012). Increasing green space in cities is important and may result in multiple co-benefits for health, the economy, society and the environment. Hence, this nature-based measure often represents a more efficient and cost-effective solution than more traditional approaches (EC 2015b). Furthermore, the future damage as a result of inaction is often more costly than the necessary investments (EEA 2012; Klein Tank and Lenderink 2009).

\subsection{Comparing Cities}

The focus of this paper has been on the performance of IWRM in European cities. Nevertheless, we have tried to include also other geographical regions. The selection of cities is therefore not random at all, but regionally biased towards western Europe. With these limitations in mind we have clustered cities into distinct categories of sustainability regarding their IWRM. The categorization is based on the $\mathrm{BCI}^{*}$ scores and the $\mathrm{CBF}$ indicators for 45 cities in 27 different countries. The suggested categorization is supported by the results of a hierarchical clustering analysis (Fig. 5). Three broad categories can be identified(Fig. 5 with squared Euclidean distance $>12$ ). One category includes most Scandinavian and Dutch cities which typically have high BCI* values varying from 6 to 8 . Next, a category including a variety of cities with average BCI* values between 4 and 6. Finally, a third category is identified that includes cities in developing and transition countries and many cities from eastern Europe. The BCI* values range from 0 to 4 . However, the developing cities (Dar es Salaam, Kilamba Kiaxi, Belém and Ho Chi Minh city) appear to be substantially different from the other cities in this category. These cities also have the lowest $\mathrm{BCI}^{*}$ values with values in the range of 0 to 2 . Moreover, these cities do not meet their basic water services such as access to drinking water and sanitation, whereas cities in the $\mathrm{BCI}^{*}$ range of 2 to 4 have almost full coverage of basic water services (Fig. 6). As basic water services are key for human life, cities which lack basic services are categorized separately. Based on Fig. 5 and the indicator scores of 45 cities, and in particular some key indicators as shown in Fig. 6, we propose a simple categorization of the different levels of sustainability for IWRM in cities (Table 5; Fig. 7).

\section{Discussion}

\subsection{IWRM Performances of Cities}

A performance-oriented set of indicators more accurately measures cities own activities and efforts to improve their IWRM. The BCI* shows a larger variation than the previous BCI, 


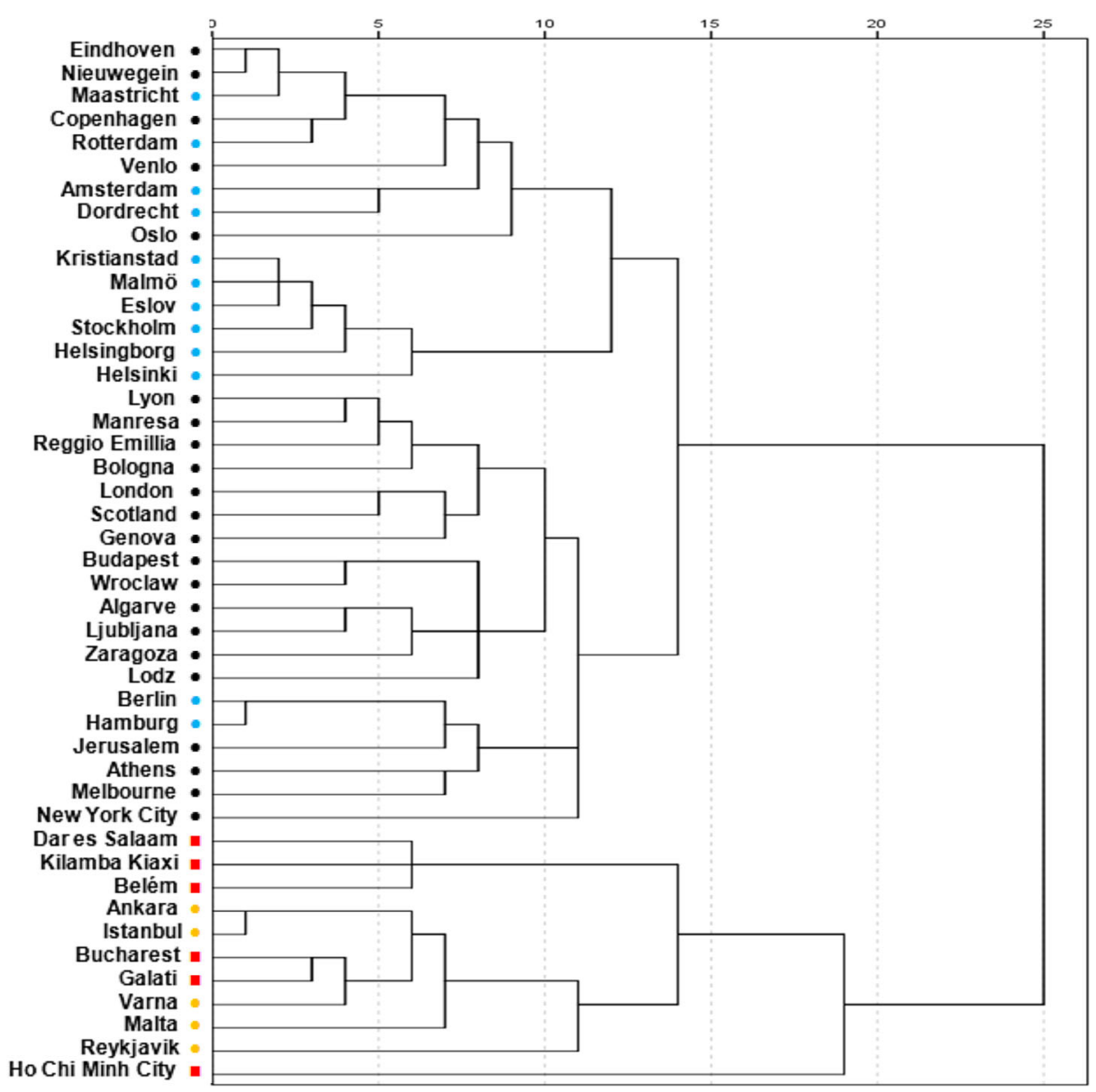

Fig. 5 Dendrogram of the City Blueprints using hierarchical clustering with the squared Euclidean distances for all 25 indicators. The cities marked red, orange, black or blue have a $\mathrm{BCI}^{*}$ between $0-2,2-4,4-6$ and 6-8, respectively. Three broad categories with squared Euclidean distance $>10$, can be identified

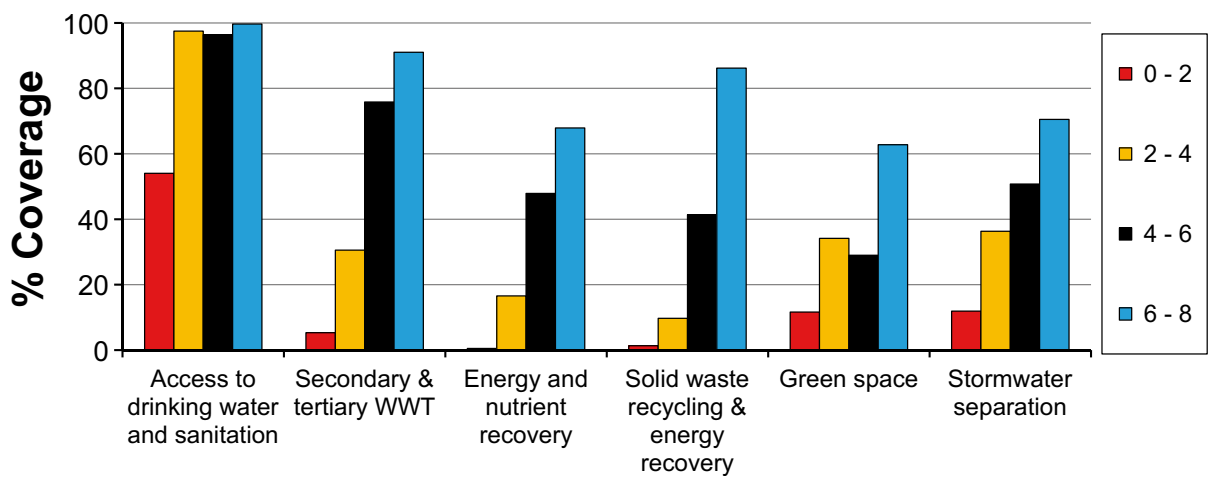

Fig. 6 Key indicators of the improved CBF. Bars represent the averages (\%) of the data for the 45 cities and regions. The columns marked red, orange, black or blue are cities with a BCI* between 0-2, 2-4, 4-6 and 6-8, respectively 
Table 5 Proposed categorization of different levels of sustainable IWRM in cities

BCI Categorization of IWRM in cities

score

0-2 Cities lacking basic water services

Access to potable drinking water of sufficient quality and access to sanitation facilities are insufficient. Typically, water pollution is high due to a lack of WWT. Solid waste production is relatively low but is only partially collected and, if collected, almost exclusively put in landfills. Water consumption is low but water system leakages are high due to serious infrastructure investment deficits. Basic water services cannot be expanded or improved due to rapid urbanization. Improvements are hindered due to governance capacity and funding gaps (Table 2).

2-4 Wasteful cities

Basic water services are largely met but flood risk can be high and WWT is poorly covered. Often, only primary and a small portion of secondary WWT is applied, leading to large scale pollution. Water consumption and infrastructure leakages are high due to the lack of environmental awareness and infrastructure maintenance. Solid waste production is high and waste is almost completely dumped in landfills. Governance is reactive and community involvement is low.

\section{4-6 Water efficient cities}

Cities implementing centralized, well-known, technological solutions to increase water efficiency and to control pollution. Secondary WWT coverage is high and the share of tertiary WWT is rising. Water efficient technologies are partially applied, infrastructure leakages are substantially reduced but water consumption is still high. Energy recovery from WWT is relatively high while nutrient recovery is limited. Both solid waste recycling and energy recovery are partially applied. These cities are often vulnerable to climate change, e.g. urban heat islands and drainage flooding, due to poor adaptation strategies, limited stormwater separation and low green surface ratios. Governance and community involvement has improved.

6-8 Resource efficient and adaptive cities

WWT techniques to recover energy and nutrients are often applied. Solid waste recycling and energy recovery are largely covered whereas solid waste production has not yet been reduced. Water efficient techniques are widely applied and water consumption has been reduced. Climate adaptation in urban planning is applied e.g. incorporation of green infrastructures and stormwater separation. Integrative, centralized and decentralized as well as long-term planning, community involvement, and sustainability initiatives are established to cope with limited resources and climate change.

8-10 Water wise cities

There is no $\mathrm{BCI}^{*}$ score that is within this category so far. These cities apply full resource and energy recovery in their WWT and solid waste treatment, fully integrate water into urban planning, have multi-functional and adaptive infrastructures, and local communities promote sustainable integrated decision making and behavior. Cities are largely water self-sufficient, attractive, innovative and circular by applying multiple (de)centralized solutions.

thereby better emphasizing the potential gain that is possible by sharing knowledge, experiences and best practices amongst cities (Fig. 2). The correlations between the BCI* and IWRM ambitions, public participation, government effectiveness and GDP for 11 cities (Van Leeuwen 2013) have been confirmed in this paper for 45 cities (Table 4). Moreover, strong correlations with ND-GAIN climate readiness $(r=0.86)$, green city index $(r=0.86)$, environmental awareness index $(r=0.86)$, and various World Bank governance indicators have been found (NDGAIN 2013; Siemens 2015; EFILWC 2012; Harju-Autti and Kokkinen 2014; World Bank 2015). This may emphasize the importance of IWRM ambitions, effective governance, community involvement and financial resources for sustainable urban IWRM.

CBF indicators scores differed largely, even between western European cities. Especially, differences in solid waste treatment appeared to be large. Only the best performing cities applied recycling and energy recovery for most of their solid waste while, unlike water 


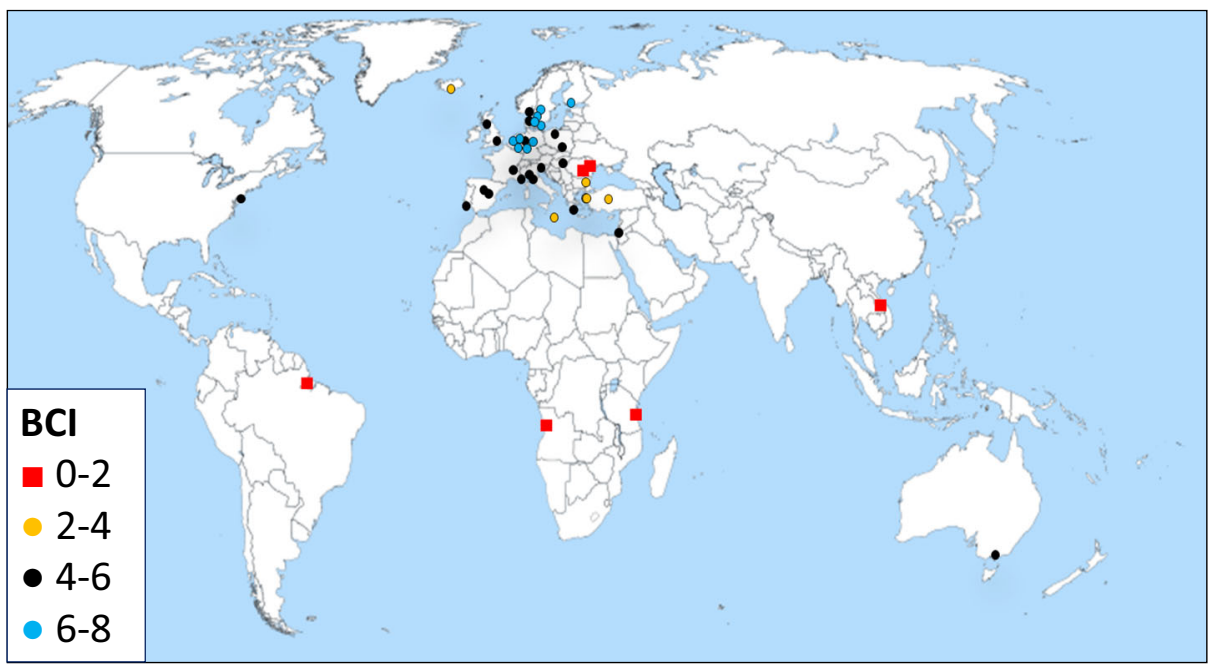

Fig. 7 Municipalities and regions that have been analyzed. Red, orange, black and blue represent municipalities and regions with an improved BCI between $0-2,2-4,4-6$ and 6-8, respectively

consumption, solid waste production was still high. The application of energy and nutrient recovering techniques was also highly variable with a lot of potential for improvements in many cities.

Cities appeared to be particularly vulnerable for flooding, heat island effects and water scarcity. Urbanization and climate change will only amplify these trends (EEA 2012) and delaying climate adaptation often results in much more expensive adaptation measures and damage costs in the long term (EEA 2007). Hence, the cost of political inaction will increase while the danger to citizens and the economy rises. For example, riverine flood losses in Europe could more than double in frequency by 2050 . However, it is estimated that by raising the flood protection standard to 1 per 100 years for all European river basins, an annual flood loss of around $€ 7$ billion is avoided whereas the associated cost to avoid this are estimated at $€ 1.75$ billion (Jongman et al. 2014). Also stormwater separation and increase in soil permeability (e.g. green space) could greatly reduce damage as a result of extreme precipitation, water pollution, water scarcity and heat waves (EEA 2012; Gill et al. 2007). Only $49 \%$ of the water infrastructures in the cities and regions in this study separated stormwater and many cities have a green space coverage of less than $15 \%$. Hence, many cities urgently need to invest in adaptation measures to decrease their climate vulnerability (EEA 2012).

About $50 \%$ of the required infrastructure investments up till 2025 is on water distribution and sewer systems (UNEP 2013) which is about $60 \%$ more than is spent in the same period until now (McKinsey 2013). Water infrastructure investment requirements are already $0.35-1.2 \%$ of the annual GDP in developed countries and much higher for developing countries (0.71-6.30\% of their annual GDP; Cashman and Ashley 2008). The infrastructure investment deficits in the assessed cities can be demonstrated clearly, for example by an average leakage rate of $21 \%$ with 7 cities exceeding $40 \%$. Importantly, infrastructure investments are not only insufficient according to current standards but investments need to be increased significantly to make the necessary climate adaptations for an, in many cases, strongly rising urban population. 


\subsection{Categorization of Cities}

For the categorization of cities, $\mathrm{BCI} *$ scores have been rounded. Consequently, the lowest and highest category are less frequently represented. Furthermore, our selection of cities is regionally biased towards western Europe. Nevertheless, the results allow for a simple heuristic categorization of the different levels of sustainability for urban IWRM (Table 5; Fig. 7). IWRM categorization in literature is scarce and the categorization proposed in this paper is the first that relies on an indicator analysis of a substantial number of cities in different countries.

Based on detailed historical, temporary and future research, Brown et al. (2009) described six hydro-social contracts concerning urban water management transitions in Australia. Furthermore, Lundin and Morrison (2002) identified four levels of environmental sustainability for the urban water infrastructure based on two case studies. Finally, based on several urban water characteristics, Van der Steen (2011) distinguished three types of cities, e.g., water management driven by; (1) basic service issues, (2) water scarcity, and (3) by climate change effects.

The first proposed category 'Cities lacking basic water service' resembles the 'Water supply city' and 'Sewered City' transition described by Brown et al. (2009), and coincides with the type 1 'Water management driven by basic service issues' (Van der Steen 2011) and level D described by Lundin and Morrison (2002). 'Wasteful cities' typically do not meet minimum standards for environmental protection and are therefore not described by Lundin and Morrison (2002). 'Water efficient cities' is a combination of level B and C described by Lundin and Morrison (2002). This category shows a high similarity with the 'Waterways City' because environmental protection and awareness are increasing while centralized water system approaches are still largely dominant (Brown et al. 2009). 'Resource efficient and adaptive cities' emphasize the integrative nature of the urban watercycle that deals with climate change and resource scarcity. This category is comparable with 'Water cycle cities' described by Brown et al. (2009) and level A described by Lundin and Morrison (2002). Unfortunately, it appeared to be difficult to find data to include the advancements in fit-forpurpose water supply systems whereas this is an important component of IWRM and characteristic for this category (Brown et al. 2009). None of the 45 cities had a BCI* categorized as 'Water wise cities' and it is unlikely that such a city will be found easily because the geometric aggregation method penalizes unbalanced indicator scores. This is in accordance with literature where a water wise or sensitive city is often assumed to be currently non-existing (Ferguson et al. 2013). However, new city quarters or future cities may realize water wise management.

There is not an accepted set of attributes and indicators that define water wise or water sensitive cities (Ferguson et al. 2013) and it is unlikely that this will be developed soon, since water wise solutions are divergent, redundant and applied on different scales. Hence, the City Blueprint is not an attempt to do this. Instead, the City Blueprint is a quick scan of the current IWRM state of cities that enables a basic comparison between cities. Consequently, high scoring cities are on the frontline of the urban transition towards water wise cities. However, this does not imply that these cities are water and climate robust. For example, extreme weather events such as in Copenhagen (EEA 2012) may still seriously affect high scoring cities that apply effective water management. Furthermore, the CBF and TPF may serve as a start for more in-depth studies in their urban strategic planning and implementation process towards water wise cities. 


\subsection{The Urgency to Improve Developing and Transitioning Cities}

The TPF provides a basic overview of the differences in social, environmental and financial situation of the 45 cities assessed (Fig. 1). The BCI* and TPI are negatively correlated ( $r=$ -0.83 ) implying that cities that experience many pressures also have low BCIs. Hence, the need to transform IWRM is urgent and extremely challenging. Currently, Belém, Dar es Salaam, Ho Chi Minh City, Istanbul and Kilamba Kiaxi experience many pressures that may seriously hamper even the first steps towards water wise cities. This is also pointed out by the highly negative correlation between TPI and the ND-GAIN climate readiness index $(r=-0.94)$. Hence, cities in countries that have low ability to absorb financial resources and mobilize them efficiently to adapt to climate change (ND-GAIN 2013) are often cities that also experience social, environmental and financial pressures according to the TPF. Accordingly, these cities typically score low on e.g. environmental awareness ( $r=-0.84)$, public participation $(r=-0.81)$, green city index $(r=-0.85)$, government effectiveness $(r=-0.88)$, as well as other World Bank governance indicators such as regulatory quality $(r=-0.90)$, voice and accountability $(r=-0.90)$ and control of corruption $(r=-0.89)$ (World Bank 2015; Harju-Autti and Kokkinen 2014; EFILWC 2012). Fast urbanization and climate change may further worsen access to basic urban services and affect quality of life in cities. The urban poorthe slum dwellers in developing countries will be most affected (UN-Habitat 2010).

Although the City Blueprint dataset is regionally biased with only a few cities in developing and transition countries (Fig. 7), the high similarity between the $\mathrm{BCI}^{*}$ and the green city index scores available for many developing and transition cities (Siemens 2015), allows for broader extrapolation of our findings (Table 4). In general, the environmental, financial and social pressures in developing and transitioning cities may seriously limit their ability to improve their IWRM, whereas the priorities to do so are both high and urgent. Our results support the findings of the OECD (2011) that bridging of the multi-level governance gaps as shown in Table 1, may greatly enhance global IWRM and strongly decrease pressures on ecosystems, on which cities strongly depend. It also supports the view put forward by UN Secretary-General Ban Ki-moon on World Water Day 2015: 'The onset of climate change, growing demand on finite water resources from agriculture, industry and cities, and increasing pollution in many areas are hastening a water crisis that can only be addressed by cross-sectoral, holistic planning and policies - internationally, regionally and globally.'

\subsection{Next Steps}

Cities may play a leading role to meet the global water challenges. Cities need to be aware that inaction is often more costly than the development of a long-term coherent strategy and implementation plan to improve their sustainability. Climate change mitigation and adaptation, water and waste are important aspects of such a coherent long-term plan. Coupling of these water-related challenges in cities can also create many win-win's or co-benefits which can bridge the funding gap (Table 1). This is what is needed in smarter cities (EC 2015a). Local authorities need simple and practical tools to improve their IWRM (EEA 2007; EEA 2014b; Gleik 2003). Cities can benefit from the experiences of other cities. Therefore, city-to-city learning (city learning alliances) and urban-rural co-operation are needed (EC 2015a; OECD 2015). Learning alliances can be used to improve awareness, communication, community involvement, governance (Table 1), and accelerate the transition towards water wise cities. Our baseline assessment is therefore key to create awareness and can serve as a first step for 
decisions makers to envision, implement and evaluate sustainable IWRM strategies. Our next steps in the City Blueprint action group will be the development of a compendium of best practices in cities and, if possible, the development of simple models that can help cities to calculate the costs and benefits of implementation measures to improve their IWRM. We would like to extend our assessments beyond Europe as the challenges for adaptive urban IWRM in other continents such as Africa and Asia are very pressing (Van Leeuwen 2013).

\section{Conclusion}

The urgency for sustainable urban IWRM is increasingly high due to global infrastructure deficits, lack of climate change adaptation and vast urbanization. In fact, the longer investments are postponed, the more expensive it will become while the danger for citizens and the economy only increases. The proposed improved CBF is more performance-oriented and therefore more accurately measures the cities' own efforts to improve their IWRM, thereby better emphasizing the potential gain that is possible by city-to-city learning. By showing key social, financial and environmental pressures, the TPF provides an overview of the most important opportunities and limitations for IWRM and may assist in prioritizing city-specific water issues. The $\mathrm{BCI}^{*}$ showed highly positive and the TPI showed highly negative correlations with, e.g. the World Bank governance indicators, the ND-GAIN climate readiness index, the environmental awareness index, green city index and public participation (Table 4). This may imply that effective governance, environmental awareness and community involvement are important for sustainable urban IWRM. The BCI* and the TPI correlated negatively $(r=$ -0.83 ) implying that cities that experience many social, environmental and/or financial pressures are associated with a low IWRM performance. These cities urgently need to improve their IWRM but face many challenges such as fast urbanization, climate change and institutional and financial barriers (Table 1). Based on the overall $\mathrm{BCI}^{*}$ and key indicators, a simple categorization is proposed (Table 5). This categorization scheme may provide a heuristic tool aimed at informing decision makers and accelerating transitions towards water wise cities.

Acknowledgments We would like to thank all city representatives for their participation in this study. In particular we would like to thank Misagh Mottaghi (Lund University in Sweden), for her work to contact and assess cities in Sweden. We would also like to thank Ciprian Nanu (EIP Water Secretariat) for his efforts to contact cities in Central and Eastern Europe. We would also like to thank Zsóka Ardai (Budapest, Hungary) for her involvement in the assessments of both Budapest and Wroclaw, and Professor Zalewski (European Regional Centre for Ecohydrology in Lodz for the assessment of Lodz. This report is a summary of activities that has been carried out over a period of more than 4 years. The City Blueprint activities started in 2011 as institutional research of KWR Watercycle Research Institute in the context of Watershare ${ }^{\mathbb{R}}$ : sharing knowledge in the water sector (http://www.watershare.eu/). The methodology has been applied in the context of the EU Research Project TRUST (Transitions to the Urban Water Services of Tomorrow) and further received funding from the Netherlands TKI Water Technology Program (Project T550004). The City Blueprint Action Group is part of the governance activity of the European Innovation Partnership on Water of the European Commission (http:// www.eip-water.eu/City_Blueprints), coordinated by both Dr. Richard Elelman of Fundació CTM Centre Tecnològic and NETWERC H2O (Manresa, Spain) and Prof. Dr. Kees Van Leeuwen of KWR Watercycle Research Institute. The European Commission is acknowledged for funding TRUST in the 7th Framework Programme under Grant Agreement No. 265122 and for BlueSCities in H2020-Water under Grant Agreement No. 642354.

Conflict of Interest No conflict of interest 
Open Access This article is distributed under the terms of the Creative Commons Attribution 4.0 International License (http://creativecommons.org/licenses/by/4.0/), which permits unrestricted use, distribution, and reproduction in any medium, provided you give appropriate credit to the original author(s) and the source, provide a link to the Creative Commons license, and indicate if changes were made.

\section{References}

Brown RR, Farrelly MA (2009) Delivering sustainable urban water management: a review of the hurdles we face. Water Sci Technol 59:839-846

Brown RR, Keath N, Wong THF (2009) Urban water management in cities: historical, current and future regimes. Water Sci Technol 59:847-855

Cashman A, Ashley R (2008) Costing the long-term demand for water sector infrastructure. Foresight 10:9-26

Chong J (2014) Climate-readiness, competition and sustainability: an analysis of the legal and regulatory frameworks for providing water services in Sydney. Water Policy 16:1-18

Cordell D, White S (2011) Peak phosphorus: clarifying the key issues of a vigorous debate about long-term phosphorus security. Sustainability 3:2027-2049

EC (2012) European Commission. Communication from the commission to the parliament, the council, the European Economic and Social Committee and the Committee of the Regions. A blueprint to safeguard Europe's water resources.COM (2012)673 final

EC (2014) European Commission: the European critical raw materials review. MEMO/14/377 26/05/2014. Brussels, Belgium http://europa.eu/rapid/press-release_MEMO-14-377_en.htm. Accessed 12 March 2015

EC (2015a) European Commission: European innovation partnership on water. Brussels, Belgium. http://www. eip-water.eu/City_Blueprints. Accessed 12 March 2015

EC (2015b) European Commission: nature-based solutions \& re-naturing cities. Final Report of the Horizon 2020 Expert Group. Brussels, Belgium

EEA (2007) European Environment Agency. Climate change: the costs of inaction and the costs of adaptation. Technical report No 13/2007, Copenhagen, Denmark

EEA (2012) European Environment Agency. Urban adaptation to climate change in Europe. Challenges and opportunities for cities together with supportive national and European policies. Synthesis, Copenhagen

EEA (2014a) European Environment Agency: performance of water utilities beyond compliance. Sharing knowledge bases to support environmental and resource-efficiency policies and technical improvements. Technical report No 5/2014, Copenhagen, Denmark

EEA (2014b) National adaptation policy processes in European countries. Report No 4/2014, Copenhagen, Denmark

EFILWC (2012) European Foundation for the improvement of living and working conditions: quality of life in Europe: impact of the crisis, Luxembourg http://eurofound.europa.eu/sites/default/files/ef_files/pubdocs/ 2012/64/en/1/EF1264EN.pdf. Accessed 15 Jan 2015

Elkington J (1998) Cannibals with forks: the triple bottom line of 21st century business. New society, Vancouver

Engel K, Jokiel D, Kraljevic A, Geiger M, Smith K (2011) Big cities big water big challenges: water in an urbanizing world. World Wildlife Fund, Berlin

Ferguson BC, Frantzeskaki N, Brown RR (2013) A strategic program for transitioning to a Water Sensitive City. Landsc Urban Plan 117:32-45

Floyd J, Iaquinto BL, Ison R, Collins K (2014) Managing complexity in Australian urban water governance: transitioning Sydney to a water sensitive city. Futures 61:1-12

Gill S, Handley J, Ennos A, Pauleit S (2007) Adapting cities for climate change: the role of the green infrastructure. Build Environ 1:115-133

Gleik PH (2003) Water use. Annu Rev Environ Resour 28:275-314

Harju-Autti P, Kokkinen E (2014) A novel environmental awareness index measured cross-nationally for fifty seven countries. Univ J Environ Res Technol 4:178-198

Hoekstra AY, Wiedman TO (2014) Humanity's unsustainable environmental footprint. Science 344:1114-1117

IMF (2013) International monetary fund: world economic outlook database http://www.imf.org/external/pubs/ft/ weo/2013/01/weodata/index.aspx. Accessed 19 Jan 2015

ISO (2014) International standards organization. Sustainable development of communities. Indicators for city services and quality of life. ISO, Geneva

Jongman B, Hochrainer-Stigler S, Feyen L, Aerts JCJH, Mechler R, Botzen WJW, Bouwer LM, Pflug G, Rojas R, Ward PJ (2014) Increasing stress on disaster-risk finance due to large floods. Nat Clim Chang 4:264-268

Klein Tank AMG, Lenderink G (2009) Climate change in the Netherlands; supplement to the KNMI'06 scenarios. KNMI, De Bilt 
Koop SHA, Van Leeuwen CJ (2015a) Assessment of the sustainability of water resources management: a critical review of the City blueprint approach in 45 Cities. Water Resour Manag (submitted)

Koop SHA, Van Leeuwen CJ (2015b) Towards sustainable water resources management: improving the city blueprint framework. Report KWR 2015.025. KWR Watercycle Research Institute, Nieuwegein, the Netherlands

Lazarevic D, Aoustin E, Buclet N, Brandt N (2010) Plastic waste management in the context of a European recycling society: comparing results and uncertainties in a life cycle perspective. Resour Conserv Recycl 55:246-259

Lundin M, Morrison GM (2002) A life cycle assessment based procedure for development of environmental sustainability indicators for urban water systems. Urban Water J 4:145-152

MacDonald RI, Weber K, Padowsk J, Flörke M, Schneider C, Green PA, Gleeson T, Eckman S, Lehner B, Balk D, Boucher T, Grill G, Montgomeryi M (2014) Water on an urban planet: urbanization and the reach of urban water infrastructure. Glob Environ Chang 27:96-105

McKinsey (2013) Infrastructure productivity: how to save \$1 trillion a year. McKinsey\&Company

Mori K, Yamashita T (2015) Methodological framework of sustainability assessment in City Sustainability Index (CSI): a concept of constraint and maximisation indicators. Habitat Int 45:10-14

ND-GAIN (2013) Notre Dame Global Adaptation Index: University of Notre Dame Global Adaptation Index. Detailed methodology report http://www3.nd.edu/ nchawla/methodology.pdf. Accessed 4 Jan 2015

]OECD (2003) Organization for Economic Co-Operation and Development: OECD environmental indicators: development, measurement and use http://www.oecd.org/dataoecd/7/47/24993546.pdf. Accessed 19 March 2015

OECD (2011) Organization for economic co-operation and development: water governance in OECD countries: a multi-level approach, OECD studies on water, OECD Publishing http://dx.doi.org/10.1787/ 9789264119284-en. Accessed 18 March 2015

OECD (2013) Organization for economic co-operation and development: environment at a glance 2013. OECD indicators. OECD Publishing http://www.oecd-ilibrary.org/environment/environment-at-a-glance-2013 9789264185715-en. Accessed 17 March 2015

OECD (2015) Organization for economic co-operation and development: water and cities. Ensuring sustainable futures. OECD studies on water. OECD Publishing http://dx.doi.org/10.1787/9789264230149-en. Accessed 20 April 2015

Philip R, Anton B, van der Steen P (2011) SWITCH training kit. Integrated urban water management in the city of the future. Module 1. Strategic planning, ICLEI, Freiburg, Germany http://www.switchtraining.eu/. Accessed 15 March 2015

Rosik-Dulewska C, Karwaczynska U, Ciesielczuk T (2007) Impact of leachate from an unsealed municipal landfill site on surface and groundwater quality. Environmental Engineering-Proceedings of the 2nd National Congress of Environmental Engineering $2007: 233-238$

Siemens (2015) Green city index. http://www.siemens.com/entry/cc/en/greencityindex.htm. Accessed 2 April 2015

SIWI (2012) Stockholm international water institute: facts and figures. Stockholm International Water Institute, Stockholm http://www.siwi.org/media/graphs-and-tables/. Accessed 8 April 2015

UNEP (2012) United Nations Environmental Program. The Fifth Global Environment Outlook (GEO-5): environment for the future we want. Switzerland, Geneva http://www.scribd.com/doc/96272256/The-FifthGlobal-Environment-Outlook-GEO-5. Accessed 13 March 2015

UNEP (2013) United Nations Environment programme. City-level decoupling. Urban resource flows and the governance of infrastructure transitions. A report of the working group on cities of the international resource panel. Swilling M, Robinson B, Marvin S, Hodson M.

UN-Habitat (2010) United Nations Human Settlements Programme: state of the world's cities 2010/2011—cities for all: bridging the urban divide. UN-Habitat http://mirror.unhabitat.org/pmss/listItemDetails.aspx? publicationID=2917. Accessed 3 April 2015

Van de Meene SJ, Brown RR, Farrelly MA (2011) Towards understanding governance for sustainable urban water management. Glob Environ Chang 21:1117-1127

Van der Steen P (2011) Application of sustainability indicators within the framework of strategic planning for integrated urban water planning. Sustainable water management in the City of the future. UNESCO-IHE, Delft

Van Leeuwen CJ (2013) City Blueprints: baseline assessment of sustainable water management in 11 cities of the future. Water Resour Manag 27:5191-5206

Van Leeuwen CJ, Bertram N P (2013) Baseline assessment and best practices in urban water cycle services in the city of Hamburg, Bluefacts. Int J Water Manag 10-16

Van Leeuwen CJ, Chandy PC (2013) The City blueprint: experiences with the implementation of 24 indicators to assess the sustainability of the urban water cycle. Water Sci Technol Water Supply 13:769-781

Van Leeuwen CJ, Sjerps RMA (2015a) The City blueprint of Amsterdam. An assessment of integrated water resources management in the capital of the Netherlands. Water Sci Technol Water Supply 15:404-410 
Van Leeuwen CJ, Sjerps R (2015b) Istanbul: the challenges of integrated water resources management in Europa's megacity. Environ Dev Sustain doi:10.1007/s10668-015-9636-z

Van Leeuwen CJ, Frijns J, Van Wezel A, Van De Ven FHM (2012) City Blueprints: 24 indicators to assess the sustainability of the urban water cycle. Water Resour Manag 26:2177-2197

Van Leeuwen CJ, Dan NP, Dieperink C (2015) The challenges of water governance in Ho Chi Minh City. Int Environ Assesm Manag doi:10.1002/ieam.1664

Wong THF, Brown RR (2009) The water sensitive city: principles for practice. Water Sci Technol 60:673-682

World Bank (2015) Worldwide governance indicators http://info.worldbank.org/governance/wgi/index.aspx\#faq. Accessed 11 March 2015

World Economic Forum (2014) Global risks 2014, 9th edn. Geneva, Switzerland. http://www3.weforum.org/ docs/WEF_GlobalRisks_Report_2014.pdf. Accessed 2 April 2015 